\title{
An Inferential Impasse in the Theory of Implicatures
}

\author{
Savas L. Tsohatzidis
}

\section{Introduction}

The goal of the Gricean theory of conversational implicatures (Grice 1975, 1989), and of several of its contemporary descendants, is to explain how utterances of sentences can be intended to convey, and can be understood as conveying, information lying beyond what they are semantically equipped to convey. The purpose of this essay is to show that the Gricean explanation of two prominent types of putative conversational implicatures faces a so far unnoticed problem when confronted with utterances that simultaneously carry implicatures of both of these prominent types. The problem, in a nutshell, is that, since the Gricean theory requires implicatures of these two types to be calculated under mutually incompatible inferential regimes, it cannot without inconsistency derive implicatures of either type when a single utterance carries both of them. After explaining how this problemwhich I will call "the problem of composite implicatures"-arises, the essay briefly indicates why it would fail to arise if certain distinctively anti-Gricean, but independently supported, assumptions about utterance interpretation were adopted.

\section{The problem of composite implicatures}

On the Gricean theory, conversational implicatures are conclusions of inferences that hearers draw, and are intended by speakers to draw, in order to maintain the presumption that speakers, in making their utterances, respect the so-called Cooperative Principle, a principle that is taken to embody the view that "talking [is] as special case or variety of...rational behavior" (Grice 1989: 28) and which Grice formulates as the prescription, "Make your conversational contribution such as is required, at the stage at which it occurs, by the accepted purpose or direction of the talk exchange in which you are engaged" (Grice 1989: 26). Furthermore, the inferences in 
question are supposed to belong to two fundamentally different types. In inferences of the first type, hereafter called Observance-Induced inferences, the hearer is supposed to derive the implicature by assuming (and assuming that she is expected to assume), on the one hand, that the speaker respects the Cooperative Principle and, on the other hand, that he does not contravene any of the so-called Conversational Maxims associated with that Principle (the Maxims of Quality, Quantity, Relation, and Manner; Grice 1989: 2627). In inferences of the second type, hereafter called Violation-Induced inferences, the hearer is supposed to derive the implicature by assuming (and assuming that she is expected to assume), on the one hand, that the speaker respects the Cooperative Principle, and, on the other hand, that he blatantly contravenes-that is, contravenes in a way that is meant to be recognized and cannot fail to be recognised-at least one of the so-called Conversational Maxims associated with that Principle. It will be noticed that since inferences of these two types incorporate obviously inconsistent assumptions-it is impossible both to contravene at least one of the Maxims and to not contravene any of them-, a minimally rational hearer could not be supposed to be jointly employing inferences of the two types in calculating any given conversational implicature.

Classic examples of utterance interpretations that, on Gricean theories, are conversational implicatures communicated by virtue of ViolationInduced inferences are the interpretations that involve recognising what are traditionally called "figures of speech"-in particular, metaphorical or metonymic uses of expressions-, and these will be hereafter called Mimplicatures. The fact, for example, that an utterance like (1) will, in many contexts, be taken to convey a proposition such as (Imp-1), John's suggestion was shot down. (Imp-1) John's suggestion was rejected.

or the fact that an utterance like (2) will, in many contexts, be taken to convey a proposition such as (Imp-2),

(Imp-2) Mary's guest is a famous person.

are supposed to be explicable by reference to inferences that essentially involve the assumption that the utterers of (1) and (2) blatantly violate, in 
speaking as they do, the Maxim of Quality, which requires of conversational participants to aim at truth ("try to make your contribution one that is true", Grice 1989: 27), and to therefore refrain from saying what they believe to be false ("do not say what you believe to be false", Grice 1989: 27). Given that it is obviously false, and hence unlikely to be believed by anyone, that a suggestion can be the object of a shooting, or that a guest can be a name, hearers of (1) and (2) are supposed to be taking speakers of these utterances to be blatantly violating the Maxim of Quality; but since these same hearers are also supposed to be taking the speakers to be respecting the Cooperative Principe, they are held to have the task of resolving the clash between their interlocutors' blatant violation of the Maxim and their interlocutor's presumed adherence to the Principle; and, according to the Gricean account, hearers resolve that clash by inferring that what their interlocutors intend to convey, and to be understood as intending to convey, by their utterances is not what those utterances semantically express but something different from what they semantically express-for example, in the case of (1) that the suggestion to which the speaker is referring was rejected, and in the case of (2) that the guest to which the speaker is referring is a famous person.

Classic examples of utterance interpretations that, on Gricean theories, are communicated by virtue of Observance-Induced inferences are the interpretations that are nowadays commonly referred to as "scalar implicatures", and which will hereafter be called S-implicatures. For example, the fact that an utterance like (3) will, in many contexts, be taken to convey a proposition such as (Imp-3),

Some of John's suggestions were rejected.

Not all of John's suggestions were rejected.

or the fact that an utterance like (4) will, in many contexts, be taken to convey a proposition such as (Imp-4),

Some of Mary's guests are famous persons.

Not all of Mary's guests are famous persons.

are supposed to be explicable by reference to inferences that essentially involve the assumption that the speakers of (3) and (4) respect not only the Cooperative Principle but also each one of the Conversational Maxims 
associated with that Principle, and in particular the Maxims of Quality and Quantity. The Gricean hearer's reasoning in these cases is supposed to proceed, and to be intended by the speaker to proceed, as follows. By virtue of assuming that the speaker of (3) or (4) respects the Maxim of Quality, the hearer infers that the speaker does believe in the truth that what is semantically expressed by the sentence he utters. By assuming, furthermore, that the speaker of (3) or (4) also respects the Maxim of Quantity, she infers that what is semantically expressed by the sentence he utters is the maximum amount of relevant information that he considers himself entitled to convey while remaining truthful. From this, the hearer infers that the speaker does not believe in the truth of what would be expressed by a certain semantically stronger sentence that he might have relevantly uttered but did not in fact utter. And from this she concludes that he invites, or at least allows, her to think that what would be expressed by that semantically stronger sentence is not true. Thus, on the assumption that the speaker of (3) is both truthful in what he says (as required by Quality) and maximally informative in what he says (as required by Quantity), his choosing to say not that all of John's suggestions were rejected, but only that some of them were rejected, leads the hearer to suppose that he does not believe that all of them were rejected, and is therefore inviting, or at least allowing, her to think that not all of them were rejected. And similarly, on the assumption that the speaker of (4) is truthful in what he says (as required by Quality) and maximally informative in what he says (as required by Quantity), his choosing to say not that all of Mary's guests are famous persons, but only that some of them are, leads the hearer to suppose that he does not believe that all of them are, and is therefore inviting, or at least allowing, her to think that not all of them are. It is worth emphasising, and it is emphasised by Grice himself (1989: 27, 371), that the assumption that a speaker, in saying what he does, is being maximally informative, and so respects the Maxim of Quantity, only makes sense if it is antecedently assumed that, in saying what he does, he is being truthful, and so respects the Maxim of Quality—the reason, as Grice (1989: 371) notes, is that "false information is not an inferior kind of information; it just is not information."

Now, a theory that purports to derive, in the Gricean way just sketched, M-implicatures via Violation-Induced inferences and S-implicatures via Observance-Induced inferences would be shown to be inadequate if there could be utterances each of which would simultaneously carry an Mimplicature and an S-implicature. For, if utterances carrying such composite 
implicatures existed, deriving the implicatures in the Gricean way would require the joint employment of a Violation-Induced inference and an Observance-Induced inference; and these two types of inference could not possibly be co-opted by a rational hearer-as Gricean hearers are supposed to be-, since co-opting them would require accepting as true the obvious contradiction that a speaker simultaneously violates at least one of the Conversational Maxims and does not violate any of them.

Unfortunately for the Gricean program, it is an easily ascertainable fact that composite implicatures of the sort just described are perfectly possible, and indeed quite common. For example, responding to an utterance like (5),

$$
\text { Have John's suggestions been rejected? }
$$

it is perfectly possible for a speaker to utter the sentence in (6),

$$
\text { Some of John's suggestions have been shot down. }
$$

and to thereby convey the implicature in (Imp-6):

(Imp-6) Not all of John's suggestions have been rejected

And responding to an utterance like (7),

$$
\text { Is it true that Mary's guests are famous people? }
$$

it is perfectly possible for a speaker to utter the sentence in (8),

$$
\text { Some of Mary's guests are big names. }
$$

and to thereby convey the implicature in (Imp-8):

(Imp-8) Not all of Mary's guests are famous people.

But the derivation of these composite implicatures is not possible on Gricean assumptions. In order to derive any S-implicature, and so the implicature involving the transition from "some of John's suggestions" to "not all of John's suggestions" in the case of (6), or the one involving the transition from "some of Mary's guests" to "not all of Mary's guests" in the 
case of (8), the Gricean hearer must employ an Observance-Induced inference; and that inference, as we saw, must begin with the hearer's assumption that the speakers of these utterances do respect the Maxim of Quality, and therefore do believe that what is semantically expressed by the sentences they utter is true. In order, on the other hand, to derive any M-implicature, and so the implicature involving the transition from "were shot down" to "were rejected" in the case of (6), or the one involving the transition from "are big names" to "are famous people" in the case of (8), the Gricean hearer must employ a Violation-Induced inference; and that inference, as we saw, must begin with the hearer's assumption that the speakers of these utterances blatantly violate the Maxim of Quality, given that they obviously do not believe that what is semantically expressed by the sentences they utter is true. However, it is incoherent to suppose that anyone can simultaneously violate and not violate the Maxim of Quality, and equally incoherent to suppose that anyone can simultaneously believe and not believe that what is semantically expressed by a certain uttered sentence is true. Therefore, a rational hearer using the resources offered her by the Gricean theory can derive neither the composite implicature communicated by (6) nor the composite implicature communicated by (8)_nor, of course, any of the many composite implicatures of a similar kind that utterances of natural language sentences can easily convey. ${ }^{1}$

\footnotetext{
1 It should be noticed, in case it isn't obvious, that the idea of a two-phased derivation of composite implicatures, in which the output of an initial Violation-Induced inference would be the input to a subsequent Observance-Induced inference, would make no Gricean sense (assuming that it would make sense at all). On such a proposal, the hearer of "Some of John's suggestions have been shot down" would first conclude, via a Violation-Induced inference, that the speaker believes that some of John's suggestions have been rejected, and then, by treating her own conclusion as if it was a further utterance by the speaker, and by applying to that imaginary speaker's utterance an Observance-Induced inference, would derive the conclusion that the actual speaker does not believe that all of John's suggestions have been rejected; and similarly, the hearer of "Some of Mary's guests are big names" would first conclude, via a Violation-Induced inference, that the speaker believes that some of Mary's guests are famous persons, and then, by treating her own conclusion as if it was a further utterance by the speaker, and by applying to that imaginary speaker's utterance an Observance-Induced inference, would derive the conclusion that the actual speaker does not believe that all of Mary's guests are famous persons. The trouble with this proposal is, of course, that Gricean inferences are supposed to be triggered by actual speakers' utterances rather than by imaginary speakers' utterances; and that, in any case, it is only regarding the former, and not the latter, type of utterance that the question as to what it implicates, and whether or not it respects any conversational principles, can significantly be answered, and so can significantly be asked.
} 
One might try to ignore the problem just outlined by declaring that the M-implicatures and S-implicatures jointly conveyable by utterances of (6) or of (8) are, despite all appearances, creatures of an entirely different kind from the M-implicatures or S-implicatures conveyable by utterances of (1)(2) or of (3)-(4), and that implicatures of that mysterious new kind lie outside the intended scope of the Gricean theory of implicatures. This is the sort of response that would protect the Gricean theory only by making it unfalsifiable, and so would not save it at all. In addition, it would be a response with extremely implausible implications for the particular cases under consideration: surely, if any mechanism explains the transition from "some" to "not all" in the examples that appear unproblematic for the Gricean account (such as (3) and (4)), the same mechanism should be able to explain the identical transition from "some" to "not all" in the examples that are demonstrably problematic for that account (such (6) and (8)); and similarly, if any mechanism explains the transitions from "was shot down" to "was rejected", or from "is a big name" to "is a famous person", in the examples that appear unproblematic for the Gricean account (such as (1) and (2)), the same mechanism should be able to explain the analogous transitions in the examples that are demonstrably problematic for that account (such as (6) and (8)). Instead, therefore, of trying to protect the Gricean doctrine by making it unfalsifiable, it would be advisable to admit that the composite implicatures conveyable by utterances like (6) and (8) do falsify it, and then consider which theoretical decisions would be consistent with recognition of this fact.

One kind of solution would be to abandon the Gricean explanation of M-implicatures in terms of Violation-Induced inferences and retain only the Gricean explanation of S-implicatures in terms of Observance-Induced inferences (assuming that the latter type of explanation would not be objectionable on independent grounds). On one option within that kind of solution, the interpretation of metaphorical or metonymic uses of expressions that an utterance may contain would be part of a contextually adjusted extension of its semantic interpretation-in other words, what are here called M-implicatures would not be instances of conversational implicature in Grice's sense of that term, and would not be 'explained' by Violation-Induced inferences of the Gricean kind-, whereas S-implicatures, which would be instances of conversational implicature in the Gricean sense, would be pragmatically derived when needed, and with no risk of inconsistency, through Observance-Induced inferences of the Gricean kind. 
A second kind of solution would be to abandon the Gricean explanation of S-implicatures in terms of Observance-Induced inferences and retain only the Gricean explanation of M-implicatures in terms of Violation-Induced inferences (assuming that the latter type of explanation would not be objectionable on independent grounds). On one option within that kind of solution, the derivation of an utterance's so-called "scalar implicatures" would be part of a contextually adjusted extension of its semantic interpretation-in other words, what are here called S-implicatures would not be instances of conversational implicature in Grice's sense of that term, and would not be 'explained' by Observance-Induced inferences of the Gricean kind-, whereas M-implicatures, which would be instances of conversational implicature in the Gricean sense, would be pragmatically derived when needed, and with no risk of inconsistency, through ViolationInduced inferences of the Gricean kind.

Finally, a third kind of solution would be to abandon both the Gricean explanation of $\mathrm{M}$-implicatures in terms of Violation-Induced inferences and the Gricean explanation of S-implicatures in terms of Observance-Induced inferences. On one option within that kind of solution, the interpretation of both the metaphorical or metonymic uses of expressions that an utterance may contain and the so-called "scalar implicatures" that an utterance may convey would be parts of a contextually adjusted extension of its semantic interpretation, and only aspects of communicated content beyond those here referred to as M-implicatures or S-implicatures could possibly be pragmatically analysed in Gricean terms.

It is not my purpose here to argue in favour of one of these types of solution and against the others, but it is clear that each type, and especially the third one, would require acknowledging that the Gricean theory is significantly less successful than its supporters take it to be: Gricean explanations of S-implicatures in terms of Observance-Induced inferences, as well as Gricean explanations of M-implicatures in terms of ViolationInduced inferences, have long been cited, and keep being widely cited, as prime examples of the explanatory fertility of the Gricean approach to the analysis of linguistic interpretation; therefore, if, as the problem of composite implicatures discussed here suggests, at least one, and possibly both, of these types of Gricean explanation cannot be sustained, the range of theoretically interesting cases that the Gricean theory can adequately cover would appear to be drastically reduced. 
The significance of this outcome would of course be enhanced if there were theoretical frameworks, alternative to the Gricean one, and developed on the basis of evidence independent of the evidence provided by composite implicatures, for which the existence of composite implicatures would be in principle unproblematic. And it seems to me that there are in fact several such frameworks, two of which I would now like to briefly mention, concentrating on what would make their treatment of composite implicatures anti-Gricean rather than on the important differences that exist between them.

As a first example, consider the treatment of what are here called Simplicatures and M-implicatures within Relevance Theory (Sperber and Wilson 1995; Carston 2002, 2010; Wilson and Sperber 2012). On that theory, the interpretative phenomena associated with these labels are not implicatures properly so called but rather explicatures-that is, representations of the explicit content of an utterance in a context - that are derived from an utterance's possibly underspecified logical form in accordance with the Principle of Relevance; and neither explicatures nor implicatures properly so called-that is, representations of the non-explicit content of an utterance in a context, also derived in accordance with the Principle of Relevance- owe their existence to speaker intentions aiming to provoke hearer inferences that invoke the Cooperative Principle and the observance or violation of Gricean Conversational Maxims. Now, an explicature, according to Relevance Theory, can involve (among other things) either the narrowing or the broadening of the conceptual content of an element present in an utterance's logical form; and what are here called Simplicatures and M-implicatures, when occurring independently of each other, could be analysed as components of explicatures resulting, respectively, from a conceptual narrowing process applied to an element present in an utterance's logical form and from a conceptual broadening process applied to an element present in an utterance's logical form. Thus, the S-implicatures involving the transition from "some of John's suggestions" to "not all of John's suggestions" in the interpretation of (3), or the transition from "some of Mary's guests" to "not all of Mary's guests" in the interpretation of (4), could be represented as components of explicatures resulting from the application of a conceptual narrowing process to appropriate elements in those utterances' logical forms; whereas the Mimplicatures involving the transition from "was shot down" to "was rejected" in the interpretation of (1), or the transition from "is a big name" 
to "is a famous person" in the interpretation of (2), could be represented as explicatures resulting from the application of a conceptual broadening process to appropriate elements in those utterances' logical forms. Notice, however, that there is nothing in Relevance Theory that prevents conceptual narrowing and conceptual broadening processes from operating in parallel, as long as they operate on distinct elements of an utterance's logical form. Consequently, Relevance Theory would have no difficulty in accounting for the fact, which a Gricean theory cannot coherently explain, that the same utterance can simultaneously convey what is here called an S-implicature and an M-implicature, as this happens in (6), in (8), and in many other utterances of a similar kind. For, these composite implicatures would simply be, in relevance-theoretical terms, explicatures resulting from the simultaneous application of a conceptual narrowing process to one element of an utterance's logical form and of a conceptual broadening process to a distinct element of the same utterance's logical form. And, of course, simultaneously applying a conceptual narrowing process to one element of an utterance's logical form and a conceptual broadening process to a different element of the same utterance's logical form is not the same thing as incoherently supposing that the utterance's speaker simultaneously violates and does not violate a Conversational Maxim, or simultaneously believes and does not believe that what is semantically expressed by the sentence that he or she utters is true.

As a second example, consider theories that have proposed, on the basis of various types of evidence that they consider to be impossible to explain under Gricean assumptions, that the interpretative phenomena here referred to as $\mathrm{S}$-implicatures or $\mathrm{M}$-implicatures do not owe their existence to reflexively intended pragmatic inferences invoking the Cooperative Principle and the observance or violation of Gricean Conversational Maxims, but are rather due to the presence, in the logical form of the utterances concerned, of dedicated silent operators that determine those utterances' semantic interpretation relative to various bodies of contextually available information. In the case of scalar phenomena, an approach of this sort is the so-called "grammatical view of scalar implicatures" developed by Chierchia and others, according to which what have here been referred to as the S-implicatures of utterances like (3) and (4) would be analysed as components of the semantic interpretation of those utterances, resulting from the interaction between a silent exhaustification operator present in the utterances' logical forms and a contextually salient set of alternatives to 
the proposition embedded under that operator (see Chierchia 2004, 2013, 2017; Chierchia, Fox and Spector 2012). In the case of phenomena like metaphor and metonymy, an approach of this sort is the so-called "demonstrative" account of figurative language initiated by Stern, according to which what have here been referred to as the M-implicatures of utterances like (1) and (2) would be analysed as components of the semantic interpretation of those utterances, resulting from the interaction between a silent "Mthat" operator-in some respects analogous to the Kaplanian "Dthat" operator-present in those utterances' logical forms and a contextually salient set of properties related to the property denoted by the predicate embedded under the "Mthat" operator (see Stern 1985, 2000, 2006, 2011). Theories like Chierchia's and Stern's have typically addressed, in their non-Gricean ways, 'pure' S-implicatures and 'pure' M-implicatures, respectively, without considering cases of utterances, such as (6) and (8) above, that simultaneously convey implicatures of both types. However, there is no good reason to suppose that they could not be combined in order to provide an account of such composite implicatures, and to thereby achieve what Gricean theories cannot achieve. The key to their combinability is the fact that the operators they respectively appeal to have different scopal properties. A Stern-type operator applies, fundamentally, to a predicate-value and delivers a different predicate-value selected from a contextually salient set of predicate-values, whereas a Chierchia-type operator applies to a proposition and delivers a different proposition constructed out of the first and of a contextually salient set of propositional alternatives to the first. In the representation of sentences conveying composite implicatures, then, the Stern-type operator would have narrow scope whereas the Chierchia-type operator would have wide scope-for example, in the representation of (6) and (8), the scopally relevant configurations would be as in $\left(6^{\prime}\right)$ and $\left(8^{\prime}\right)$, respectively, where $Z$ stands for the Chierchia-type operator and $Y$ for the Stern-type operator:

[Z [Some of John's suggestions [Y [were shot down]]]] [Z [Some of Mary's guests [ $Y$ [are big names]]]]

And the interpretation would proceed, in the standard way, by first computing the effect of the narrow-scope Stern-type operator and by then computing the effect of the wide-scope Chierchia-type operator. The overall interpretation would thus encompass both the M-implicature (as a result of 
the first computation) and the S-implicature (as an entailment of the result of the second computation). It is clear, however, that representing a composite implicature as the compositional outcome of semantic processes triggered by scopally distinct operators in the logical form of the utterance carrying it is not the same thing as 'explaining' the implicature by supposing that hearers of the utterance carrying it incoherently assume (and are intended by the speaker to incoherently assume) that the speaker both contravenes and does not contravene a Conversational Maxim, or both believes and does not believe that what is semantically expressed by the sentence he or she utters is true.

\section{Conclusion}

It would be an interesting further task, which I will not undertake here, to examine which one of the two types of non-Gricean approach very briefly sketched in the preceding two paragraphs would offer, when articulated in detail, the best account of composite implicatures. My concern has been simply to argue that, although each of these approaches has been designed to overcome defects of the Gricean approach that are independent of the specific problem of composite implicatures, neither of them is conceptually precluded, as the Gricean approach is, from addressing that problem as well. If that is correct, what have here been described as composite implicatures should be added to the growing list of phenomena that suggest that what may appear as areas of interpretation paradigmatically amenable to a Gricean treatment turn out on closer inspection to be areas that can be adequately approached only if fundamental tenets of the Gricean program are jettisoned. 


\section{References}

Carston, Robyn. 2002. Thoughts and utterances: The pragmatics of explicit communication. Oxford: Blackwell.

Carston, Robyn. 2010. Explicit communication and 'free' pragmatic enrichment. In Belén Soria \& Esther Romero (eds), Explicit communication: Robyn Carston's pragmatics, 217-285. New York: Palgrave Macmillan.

Chierchia, Gennaro. 2004. Scalar implicatures, polarity phenomena, and the syntax/semantics interface. In Adriana Belletti (ed.), Structures and beyond, 39-103. Oxford: Oxford University Press.

Chierchia, Gennaro. 2013. Logic in grammar: Polarity, free choice, and intervention. Oxford: Oxford University Press.

Chierchia, Gennaro. 2017. Scalar implicatures and their interface with grammar. Annual Review of Linguistics 3. 245-264.

Chierchia, Gennaro, Danny Fox \& Benjamin Spector. 2012. Scalar implicature as a grammatical phenomenon. In Claudia Maierborn, Klaus von Heusinger \& Paul Portner (eds), Semantics: An international handbook of contemporary research, Vol. III, 2297-2331. Berlin \& Boston: De Gruyter.

Grice, Paul. 1975. Logic and conversation. In Peter Cole \& Jerry L. Morgan (eds), Syntax and semantics, Vol. 3: Speech acts, 41-58. New York: Academic Press.

Grice, Paul. 1989. Studies in the way of words. Cambridge, Mass.: Harvard University Press.

Sperber, Dan \& Deirdre Wilson. 1995. Relevance: Communication and cognition. Second Edition. Oxford: Blackwell.

Stern, Josef. 1985. Metaphor as demonstrative. Journal of Philosophy 82. 677710.

Stern, Josef. 2000. Metaphor in context. Cambridge, Mass.: The MIT Press.

Stern, Josef. 2006. Figurative language. In Michael Devitt \& Richard Hanley (eds), The Blackwell guide to the philosophy of language, 168-185. Oxford: Blackwell.

Stern, Josef. 2011. Metaphor and minimalism. Philosophical Studies 153. 273298.

Wilson, Deirdre \& Dan Sperber. 2012. Meaning and relevance. Cambridge: Cambridge University Press. 